\title{
Cleaner of Raw Cotton with a Screw Working Body
}

Ibrat Razhabov, Abdukhalil Safoyev, Mirkhosil Agzamov*, Djaloliddin Yuldashev

Department of technological machines and equipment, Tashkent Institute of Textile and Light Industry, Uzbekistan

DOI: $10.36348 /$ sjet.2020.v05i10.003

| Received: 29.09.2020 | Accepted: 13.10.2020 | Published: 18.10 .2020

*Corresponding author: Mirkhosil Agzamov

Abstract

The article presents research materials to ensure an increase in the intensity of purification of raw cotton from fine litter in a ginnery. It is indicated that in existing cleaners of raw cotton from impurities, the process is mainly carried out due to the shock-disintegrating effect of the working bodies of the machine on the processed material. To improve the efficiency of cleaning raw cotton from fine litter, it is proposed to use a cleaner with different types of working bodies, and such a combined fine litter cleaner consisting of a ring and screw working body has been developed. Experimental studies have found that with the use of such a cleaner there is an increase in the cleaning effect by $5 \%$ (abs.). The theory of the movement of an isolated material point (leafjets of raw cotton) in a screw working body is considered. It has been determined that at an optimum angle of elevation of the helix, the maximum axial speed and productivity of the screw working body of the cleaner are ensured. It is indicated that the critical radii establish the boundaries of the regions where the material particles acquire the screw angular velocity $\omega_{0}$ and their axial displacement ceases.

Keywords: raw cotton, peg drum, screw cleaner, cleaning effect, passive impurities, active impurities.

Copyright () 2020 The Author(s): This is an open-access article distributed under the terms of the Creative Commons Attribution 4.0 International License (CC BY-NC 4.0) which permits unrestricted use, distribution, and reproduction in any medium for non-commercial use provided the original author and source are credited.

\section{INTRODUCTION}

The widespread introduction of high-speed high-performance technological machines in the textile industry requires the use of high-quality cotton fiber, which poses great challenges for the ginning industry. The principle of operation of annular and serrated drums is based on the shock-shaking effect on the processed material (raw cotton) and when dragging them along the grate to remove debris. These drums have different peripheral speeds, ring drums rotate with a peripheral speed of $9 \mathrm{~m} / \mathrm{s}$, and serrated drums rotate with a peripheral speed of $7 \mathrm{~m} / \mathrm{s}$ [1].

In general, the existing operating modes of the raw cotton cleaner drums contribute to the satisfactory cleaning of raw cotton, however, the appearance of the so-called "difficult to clean" raw cotton varieties and, therefore, a sharp decrease in the cleaning effect of machines in the processing of such raw cotton, requires research new opportunities to increase the cleaning effect of machines [2].

To intensify the cleaning process of raw cotton from small weed impurities, through the use of combined working bodies, a cleaner was developed, the use of which helps to increase the cleaning effect by 10 $12 \%$ (reg.) [3].
In this cleaner, created on the basis of a $1 \mathrm{XK}$ type cleaner that has been used for many years and has eight peg drums, a screw conveyor was used instead of the last four peg drums (Fig-1).

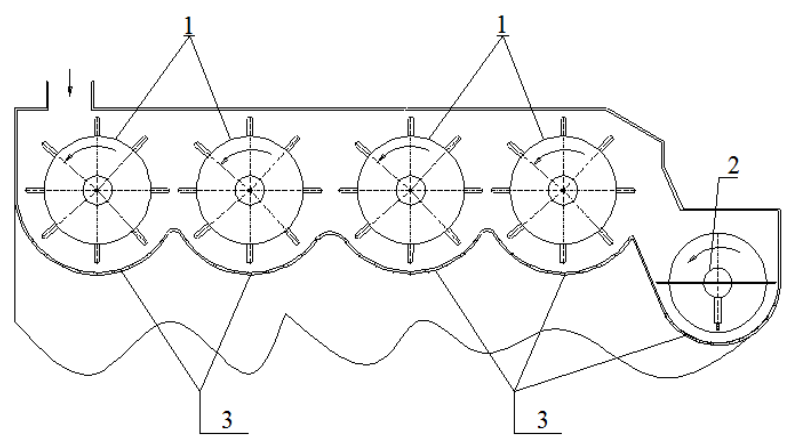

1-peg drum; 2-peg screw; 3-reticulated surface. Fig-1: Combined cleaner scheme

This decision was made due to the fact that the use of the same working bodies in a row, in this case peg drums, does not contribute to a proportional increase in the cleaning effect, on the contrary, the last peeling drums have a low cleaning effect, and the use of a screw working body increases the intensification of 
Ibrat Razhabov et al., Saudi J Eng Technol, October, 2020; 5(10): 361-365

the cotton cleaning process - raw materials from impurities.

Numerous works have been devoted to theoretical and experimental research of the operation of ring drums of cleaners, as a result of which their

\section{THEORY}

Considering the theory of motion of an isolated material point, in this case, raw cotton flocks, main parameters and operating modes have been determined [4].

Therefore, this work carried out a theoretical analysis of the screw section of the cleaner to determine its modes and parameters.

in a screw cleaner (conveyor) the equation with an angular parameter for any screw conveyor can be written in the following form [5]:

$$
\frac{\mathrm{f}_{2}\left[\omega_{0}^{2} \mathrm{rsin}^{2} \alpha \cos ^{2} \beta+\mathrm{g} \sin \gamma \cos \varepsilon \sin ^{2}(\alpha+\beta)\right]\left[\cos \beta-\sin \beta \operatorname{tg}\left(\alpha+\varphi_{1}\right)\right]}{\operatorname{gsin}^{2}(\alpha+\beta)\left[\cos \gamma \operatorname{tg}\left(\alpha+\varphi_{1}\right)-\sin \gamma \sin \varepsilon\right]}=1
$$

A $\gamma=90^{\circ}$ equation (1) will relate to a horizontal, as in our case, screw conveyor.

To determine the limiting modes and parameters of the screw conveyor from equation (1) follows

$$
\left[\cos \beta-\sin \beta \operatorname{tg}\left(\alpha+\varphi_{1}\right)\right]==\frac{g \sin ^{2}(\alpha+\beta)\left[\cos \gamma \operatorname{tg}\left(\alpha+\varphi_{1}\right)-\sin \gamma \sin \varepsilon\right]}{\mathrm{f}_{2}\left[\omega_{0}^{2} \operatorname{rsin}^{2} \alpha \cos ^{2} \beta+\operatorname{gsin} \gamma \cos \varepsilon \sin ^{2}(\alpha+\beta)\right]}
$$

In the denominator of equation (2), all quantities except $\omega_{0}^{2}$, have a finite value. As $\omega_{0} \rightarrow \infty$ we have;

$$
\cos \beta-\sin \beta \operatorname{tg}\left(\alpha+\varphi_{1}\right)=0 ; \beta=90^{\circ}-\left(\alpha+\varphi_{1}\right)
$$

For a horizontal screw with $\gamma=90^{\circ}$ expression (3) is obtained independently of $\omega_{0}$, i.e. in any mode, if we keep in mind $\varepsilon=0$.

For all types of screw conveyors, no matter how large the value of $\omega_{0}$, the average value of the angle $\beta$ cannot exceed the value according to formula (3). But in the horizontal and inclined conveyors there are generators along which the particle moves parallel to the axis of the screw, i.e. when $\beta=90^{\circ}$.

$$
v_{1}=v \sin \beta=\omega_{0} r \operatorname{tg} \alpha
$$

In this case, equation (1) takes the form

$$
\mathrm{f}_{2} \sin \gamma \cos \varepsilon=-\cos \gamma+\frac{\sin \gamma \sin \varepsilon}{\operatorname{tg}\left(\alpha+\varphi_{1}\right)}
$$

When replacing $\gamma=90^{\circ}-\delta$, where $\delta$ is the angle of inclination of the screw axis to the horizontal, expression (4) takes the form

$$
\mathrm{f}_{2} \sin \gamma \cos \varepsilon=-\sin \gamma+\frac{\cos \delta \sin \varepsilon}{\operatorname{tg}\left(\alpha+\varphi_{1}\right)}
$$

For horizontal conveyor $\delta=0$

$$
\begin{aligned}
\mathrm{f}_{2} \cos \varepsilon=\frac{\sin \varepsilon}{\operatorname{tg}\left(\alpha+\varphi_{1}\right)} ; \\
\operatorname{tg} \varepsilon=\mathrm{f}_{2} \operatorname{tg}\left(\alpha+\varphi_{1}\right)
\end{aligned}
$$

It follows from (7) that, deviating from the lowest position $\varepsilon=0$ by an angle

$$
\varepsilon_{0}=\operatorname{arctg} f_{2} \operatorname{tg}\left(\alpha+\varphi_{1}\right)
$$

A particle in a horizontal conveyor for any $\omega_{0}$ moves along the generator with speed according to formula (4).

For inclined screw conveyor

$$
\varepsilon_{\mathrm{H}}=\varepsilon_{0}
$$

Where

$$
\lambda=\arcsin \left[\operatorname{tg} \delta \operatorname{tg}\left(\alpha+\varphi_{1}\right) \cos \varepsilon_{0}\right]
$$

So that the particle in the lowest position $\varepsilon=0$ does not have axial displacement, it is necessary $\beta=0, v_{1}=0$.

In this case, from equation (1) we have

$$
\omega_{0}=\sqrt{\frac{g \cos \gamma \operatorname{tg}\left(\alpha+\varphi_{1}\right)}{\mathrm{f}_{2} \mathrm{r}}-\frac{\mathrm{gsin} \gamma}{\mathrm{r}}}
$$

For horizontal screw conveyor

$$
\omega_{0}=\sqrt{-\frac{\mathrm{g}}{\mathrm{r}}}
$$

Which is impossible.

This is clear, since in the horizontal conveyor with $\varepsilon=0$ the angle $\beta$ necessarily corresponds to (3) and can be equal to zero provided that

$$
\alpha=90^{\circ}-\varphi_{1}
$$

Those with an irrational value of the angle of elevation of the helix, when the screw cannot transport the material.

It is advisable to introduce such an angle $\varphi_{\text {av }}$ between the absolute and portable velocity vectors with which the point moves in the concrete conveyor under consideration with a constant axial speed.

We have

$$
\begin{aligned}
& v_{1 \mathrm{av}}=v_{\mathrm{zav}}=v \sin \beta_{\mathrm{av}}=\frac{\omega_{0} \mathrm{r} \sin \alpha \sin \beta_{\mathrm{cp}}}{\sin \left(\alpha+\beta_{\mathrm{cp}}\right)} \\
& \omega_{\mathrm{av}}=\omega_{\theta} \frac{\sin \alpha \sin \beta_{\mathrm{av}}}{\sin \left(\alpha+\beta_{\mathrm{av}}\right)}
\end{aligned}
$$


conveyor shaft

Where $\omega_{\theta}=\omega_{0}$ is the angular velocity of the

$$
\omega_{\mathrm{av}}=\sqrt{\frac{\mathrm{gtg}\left(\alpha+\varphi_{1}\right) \cos \gamma}{\mathrm{rf}_{2}\left[\cos \beta_{\mathrm{cp}}-\sin \beta_{\mathrm{av}} \operatorname{tg}\left(\alpha+\varphi_{1}\right)\right]}}
$$

Of particular interest is the optimal angle of elevation of helical lines. At a favorable angle of elevation of the helical lines, the maximum axial speed and productivity of the screw conveyor are ensured.

In a horizontal screw conveyor, when $\gamma=90^{\circ}, \cos \gamma=0$, from formula (16) it follows

$$
\alpha_{\Gamma}=\frac{\operatorname{arctg} \infty}{2}-\frac{\varphi_{1}}{2}=45^{0}-\frac{\varphi_{1}}{2}
$$

A characteristic parameter is the critical radii in screw conveyors.

The critical radii establish the boundaries of the area where the particles of the material acquire the screw angular velocity $\omega_{0}$ and their axial displacement ceases.

From the equation (1), after replacing $\gamma=90^{\circ}-\delta, \beta=0$ it follows

$$
\frac{\mathrm{l}_{2}\left(\omega_{0}^{2} \mathrm{r}+\mathrm{g} \cos \delta \cos \varepsilon\right)}{\mathrm{g}\left[\sin \delta \operatorname{tg}\left(\alpha+\varphi_{1}\right)-\cos \delta \sin \varepsilon\right]}=1
$$

In equation (18), we can consider $\omega_{0}$ as the desired quantity, with $r$ and $\alpha$ corresponding to the peripheral helix of the conveyor.

For any $\omega_{0}$, we have

$$
\mathrm{r}_{\mathrm{cr}}=\frac{\mathrm{g}\left[\sin \delta \operatorname{tg}\left(\alpha+\varphi_{1}\right)-\cos \delta \sin \varepsilon-\mathrm{f}_{2} \cos \delta \cos \varepsilon\right]}{\mathrm{f}_{2} \omega_{0}^{2}}
$$

Using this equation, we can establish the influence of all parameters on the value of $\mathrm{r}_{\mathrm{cr}}$

For a horizontal conveyor $\left(\delta=0^{0}\right)$

$$
\mathrm{r}_{\mathrm{cr}}^{2}=\frac{\mathrm{g}\left[-\sin \varepsilon-\mathrm{f}_{2} \cos \varepsilon\right]}{\mathrm{f}_{2} \omega_{0}^{2}}
$$

In this case, the influence of $\alpha$ and $r$ at the periphery and step $S$ on $r_{\mathrm{cr}}^{2}$ falls out. In the lowest position, $\varepsilon=0, \mathrm{r}_{\mathrm{cr}}^{2}$ has an imaginary value.

The physical meaning of this is clear, since in a horizontal conveyor, under any conditions, the body begins to move at an angle $\beta=90^{\circ}-\left(\alpha+\varphi_{1}\right)$. However, there may be a case when $\beta=0$ and $\alpha_{\text {cr }}=$ $90-\varphi_{1}$.

Where in

$$
\mathrm{S}=2 \pi \mathrm{r}_{\mathrm{cr}}^{2} \operatorname{tg} \alpha_{\mathrm{cr}}=2 \pi \mathrm{r}_{\mathrm{cr}}^{2} \operatorname{tg} \alpha_{\mathrm{cr}} \varphi_{1}=\frac{2 \pi \mathrm{r}_{\mathrm{cr}}^{2}}{\mathrm{f}_{1}}
$$

Where

$$
\mathrm{r}_{\mathrm{cr}}^{2}=\frac{\mathrm{Sf}_{1}}{2 \pi}
$$

It is important to find out what value $\mathrm{r}_{\mathrm{cr}}^{2}$ will have in the position at an angle $\varepsilon=0$, determined from the condition $\operatorname{tg} \varepsilon_{0}=\operatorname{tg} \varepsilon=\mathrm{f}_{2} \operatorname{tg}\left(\alpha+\varphi_{1}\right)$. When a body in a horizontal conveyor necessarily moves parallel to the axis along the forming the cylinder of the casing [3].

Substituting into equation (20), we find

$$
\mathrm{r}_{\mathrm{cr}}^{2}=-\frac{\mathrm{g}\left[\mathrm{tg}\left(\alpha+\varphi_{1}\right)+1\right]}{\mathrm{f}_{2} \omega_{0}^{2} \sqrt{1+\mathrm{f}_{2}^{2} \operatorname{tg}\left(\alpha+\varphi_{1}\right)}}=\mathrm{f}\left(\alpha, \mathrm{f}_{1}, \mathrm{f}_{2}, \omega_{0}\right)
$$

\section{METHODOLOGY}

At the next stage of the work, the influence of design and operational factors on the performance of screw conveyors was investigated.

The value of the axial speed of the material in the screw conveyors is influenced by the angle of inclination of the screw axis $\gamma$; radius $\mathrm{r}$, tilt angle $\alpha$, angular velocity $\omega_{0}$, the friction coefficients of the material $\mathrm{f}_{1}$ and $\mathrm{f}_{2}$.

As a result of the calculations, it was established for the conveyor with parameters $r=0,150$ $\mathrm{m} ; \alpha=30 ; \mathrm{f}_{1}=0,5 ; \mathrm{f}_{2}=0,5 ; \mathrm{n}_{0}=320 \frac{\text { об }}{\text { мин }}$, that the curve of the change in the average axial speed has the form of a sine wave and is described by the equation

$$
\vartheta_{1 \mathrm{av}}=a\left(\frac{\gamma}{\gamma_{1}}-\frac{1}{2 \pi} \sin \frac{2 \pi}{\gamma_{1}} \gamma\right)
$$

where $\mathrm{a}$ - is the coefficient to be determined $\gamma_{1}$ - quarter function period, equal in this case to $90^{\circ}$.

Calculating the average value of the axial velocity by the formula

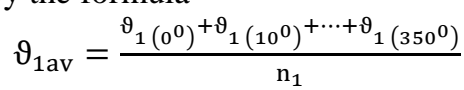

For conveyors with specific parameters when $\varepsilon=0 ; 10^{\circ}, 20^{\circ}, \ldots, 350^{\circ}$ it can be get all the necessary information.

In particular, when changing $\mathrm{f}_{1}$ in the range from $0 \quad$ to $1.0 ; \quad f_{2}=0 \div 1,0 ; \alpha=5 \div 60^{0} ; \quad r=0,025 \div$ $0,3 \mathrm{~m} ; \mathrm{n}_{0}=10 \div 500 \mathrm{мин}^{-1} ; \gamma=0 \div 90^{0} \quad ; \quad$ calculations indicate that in all cases

$$
\vartheta_{1 \mathrm{av}}^{\mathrm{b}}<\vartheta_{1 \mathrm{av}}^{\mathrm{H}}<\vartheta_{1 \mathrm{av}}^{\mathrm{z}}
$$

This phenomenon is also found when considering comparative diagrams $\vartheta_{1 \mathrm{av}}^{\mathrm{b}}$ depending on $\mathrm{f}_{1}, \mathrm{f}_{2}, \alpha_{0}, \mathrm{r}, \mathrm{n}_{0}$; built for horizontal conveyor (Fig-2).

In the horizontal conveyor,

$$
\delta=0, \omega_{0}-\omega \sqrt{\sin \delta}=\omega_{0} .
$$

Physically, this means that in a horizontal conveyor, such as the screw cleaning section we have adopted, the particle, having started moving from a lower position at $\beta$ according to (3), will necessarily reach the forming at an angle $\varepsilon_{0}$ according to (8) and move along it with a translational speed скоростью $\vartheta_{1}$ along (4). 
Table-1: The cleaning effect of the existing and experimental cleaner on the varieties of raw cotton "An-Bayaut"

\begin{tabular}{|c|c|c|c|c|c|c|c|}
\hline \multirow[t]{2}{*}{ № } & \multirow[t]{2}{*}{$\begin{array}{l}\text { Variety of } \\
\text { raw cotton }\end{array}$} & \multirow[t]{2}{*}{$\begin{array}{l}\text { Cotton } \\
\text { grade }\end{array}$} & \multirow[t]{2}{*}{$\begin{array}{l}\text { Preliminary } \\
\text { weediness, \% }\end{array}$} & \multicolumn{2}{|c|}{$\begin{array}{l}\text { Contamination of processed } \\
\text { raw cotton after cleaner, } \%\end{array}$} & \multicolumn{2}{|c|}{$\begin{array}{l}\text { The cleaning effect of } \\
\text { cleaner, \% }\end{array}$} \\
\hline & & & & existing & experimental & existing & experimental \\
\hline \multirow[t]{5}{*}{1} & \multirow[t]{5}{*}{ An-Bayout } & 1 & 3.45 & 2.06 & 1.81 & 40.3 & 47.5 \\
\hline & & 2 & 4.35 & 2.32 & 2.1 & 46.7 & 51.7 \\
\hline & & 3 & 4.9 & 2.79 & 2.21 & 43.1 & 54.9 \\
\hline & & 4 & 5.2 & 2.84 & 2.51 & 45.4 & 51.7 \\
\hline & & 5 & 5.5 & 2.93 & 2.59 & 46.7 & 52.9 \\
\hline \multirow[t]{5}{*}{2} & \multirow[t]{5}{*}{ Sultan } & 1 & 3.8 & 2.42 & 2.15 & 36.3 & 43.4 \\
\hline & & 2 & 4.3 & 2.78 & 2.48 & 35.3 & 42.3 \\
\hline & & 3 & 4.56 & 2.89 & 2.69 & 36.6 & 41.0 \\
\hline & & 4 & 5.11 & 3.25 & 2.96 & 36.4 & 42.0 \\
\hline & & 5 & 5.43 & 3.45 & 3.11 & 36.5 & 42.7 \\
\hline
\end{tabular}

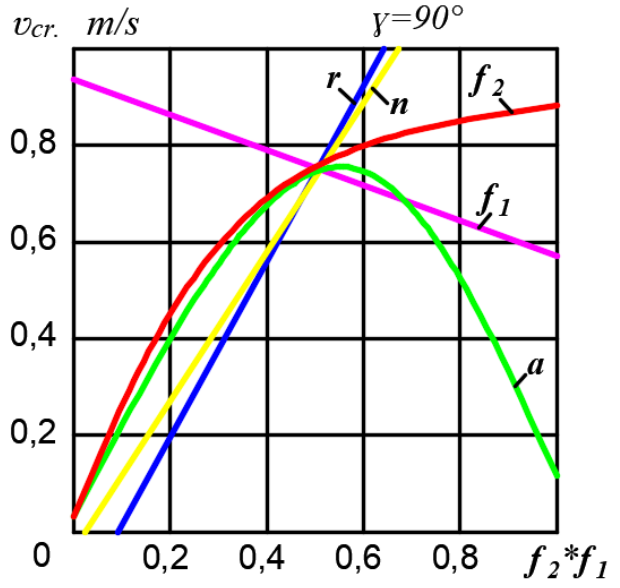

Fig-2: The graph of the change in the average axial $\vartheta_{1 \mathrm{av}}$ in the horizontal conveyor

\section{RESULTS AND DISCUSSION}

The aim of research is to develop modernized technology of primary processing of raw cotton which allows to reduce the cost of electricity, as well as loss of production, improve the quality of produced products [6].

For experimental studies, a special purifier installation with a screw organ was made, the general view of which is shown in Fig-3.

The experimental technique was as follows: prototypes of raw cotton weighing $25 \mathrm{~kg}$ were prepared, first, the initial clogging of raw cotton was determined using the LKM device, then the prototypes were passed through an experimental setup and, for comparison, through a $1 \mathrm{XK}$ type cleaner used in industry. The weediness of the processed raw cotton was determined and, through it, according to a known method, the cleaning effect. The confidence limits of the values of debris in cotton and defects in the fiber were determined with a confidence level of 0.95 [7-10].

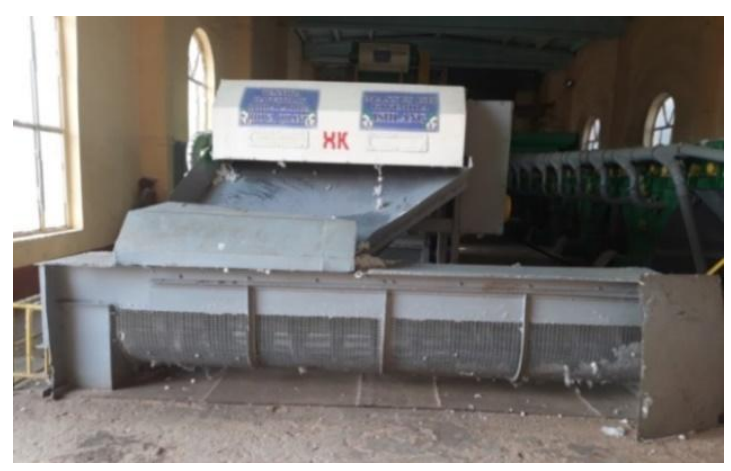

Fig-3: Recommended screw cleaner

An analysis of the results of the experiments shown in Table-1 shows that the use of a combined cleaner, combining annular and screw working bodies, improves the cleaning effect, for example, when processing raw cotton of the An-Bayavut variety, 2nd grade, this increase is $5 \%$ (abs.).

According to the data given in Table-1, the following graphs are constructed that show how effective the experimental cleaner is compared to the existing ones. In Fig-4 shows the cleaning effect of existing and recommended cleaners for five varieties of raw cotton "An-Bayaut". Accordingly in Fig-5 shows the cleaning effect of existing and recommended cleaners for five varieties of raw cotton "Sultan".

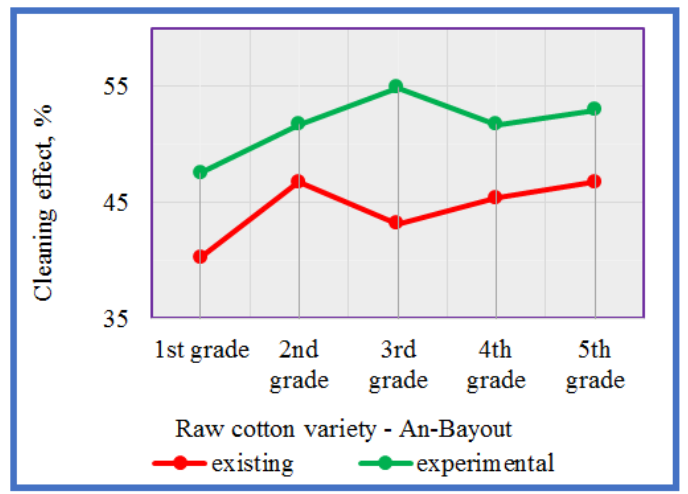

Fig-4: The cleaning effect of the existing and experimental cleaner on the varieties of raw cotton "An-Bayaut" 


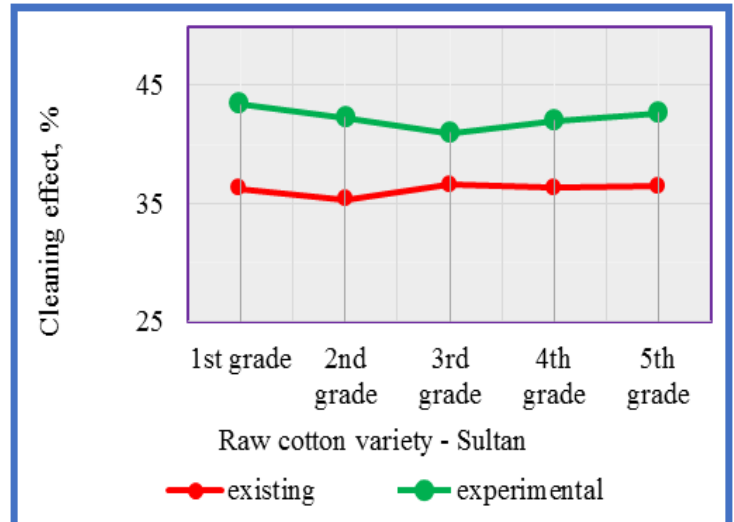

Fig-5: The cleaning effect of the existing and experimental cleaner on the varieties of raw cotton "Sultan"

\section{CONCLUSIONS}

It has been determined that at the optimum angle of elevation of the helix, the maximum axial speed and productivity of the screw working body of the cleaner are ensured.

It is indicated that critical radii establish the boundaries of the region where the material particles acquire the screw angular velocity $\omega_{0}$ and their axial displacement ceases.

Experimental studies have shown the fact that the cleaning effect is increased when using, along with ring drums, a screw working body, by $5 \%$ (abs.).

\section{REFERENCES}

1. "Primary processing of cotton" turtorial, Tashkent, 2019, 252-254.

2. Safoyev, A. A. (2015). To the problems of cleaning of hard-cards raw cotton. Journal of Textile science and Engineering, 5: 52.
3. Razhabov, I. Y., \& Safoyev, A. A. (2019). Providing an increase of the intensity of cleaning cotton from small litter, Journal Problems of textile TITLI, Tashkent, 2:12-16.

4. Madumarov, I. D. (2019). Increase efficiency of cotton cleaning based on optimization of heat and humidity conditions of cotton. Doc. Diss. - TITLI, Tashkent, 75-106.

5. Grigoryev, A. M. (1972). Screw conveyors turtorial, Moscow, Машиностроение, 55-72.

6. Agzamov, M. M., Yunusov, S. Z., \& Gafurov, J. K. (2017, October). On the technological development of cotton primary processing, using a new drying-purifying unit. In IOP Conference Series: Materials Science and Engineering (Vol. 254, No. 8, p. 082017). IOP Publishing.

7. Agzamov, M., Inagamov, A. K., \& Agzamov, M. M. (2018). Studying the Efficiency of the New Cotton Regenerator. American Journal of Mechanical and Materials Engineering, 2(4), 3339.

8. Agzamov, M., Agzamov, M. M., \& Madgidov, G. F. (2007). Ways for Improvement of Cotton Fiber Quality in Process of Ginning. Izvestiia-Vysshie Uchebnye Zavedeniia Tekhnologiia Tekstil'noi Promyshlennosti, 3, 34-37.

9. Makhkamov, R. G., \& Agzamov, M. (2006). Sampling Quenching Parameters of Ginning and Linter Grid Bars. Izvestiia-Vysshie Uchebnye Zavedeniia Tekhnologiia Tekstil'noi Promyshlennosti, 2, 101

10. Agzamov, M. (2007). Studying of New Gin Stand with Small Size Ginning Box. Izvestiia-Vysshie Uchebnye Zavedeniia Tekhnologiia Tekstil'noi Promyshlennosti, 1, 26. 